\title{
PROFESSORES INICIANTES DE LÍNGUA IN- GLESA: CONFLITOS E RE/ESTRUTURAÇÕES NO PROCESSO DE DESENVOLVIMENTO PROFISSIONAL
}

\author{
BEGINNING IN SERVICE ENGLISH \\ LANGUAGE TEACHERS: CONFLICTS AND \\ RESTRUCTURING IN THE PROCESS OF \\ PROFESSIONAL DEVELOPMENT
}

\author{
Ademar da SILVA* \\ Denise M. MARGONARI ${ }^{* *}$
}

\begin{abstract}
Resumo: Este trabalho é resultado de uma pesquisa na área de formação de professores de Língua Inglesa que visa a acompanhar a trajetória profissional dos professores em início de carreira, egressos, no ano de 2002, de um curso de Licenciatura em Letras de uma instituição pública do interior do Estado de São Paulo. Tendo em vista que muitos aspectos do processo de construção e organização da experiência humana se refletem na linguagem, na investigação desenvolvida, cruzamos a análise de trechos de relatórios e questionários de alunos egressos da disciplina Prática de Ensino e Estágio Supervisionado em Língua Inglesa I e II com dados desses alunos já em serviço. O objetivo é demonstrar que a sensação de insegurança e ansiedade quanto à futura atuação profissional, vivenciada durante o curso, ainda se manifesta no início da carreira docente e que, além de ser, muitas vezes, superada, ela varia de acordo com o perfil do aluno-professor, que, numa fase de exploração de possibilidades profissionais, estrutura e reestrutura as diversas opções que a vida lhe oferece.
\end{abstract}

\footnotetext{
* Professor Assistente Doutor do Departamento de Metodologia de Ensino da Universidade Federal de São Carlos (UFSCar). E-mail para contato: demas@power.ufscar.br

${ }^{* *}$ Professora Doutora em Educação Escolar, substituta contratada no Departamento de Metodologia de Ensino da UFSCar. E-mail para contato: denisemargonari@yahoo.com
} 
Professores iniciantes de Língua Inglesa: conflitos e re/estruturações...

Palavras-chave: Formação de professores. Língua Inglesa. Re/estruturações.

Abstract: This paper is the result of a research in the English teacher education field whose goal is to follow the professional development of in-service teachers who studied Modern Languages in an undergraduate program at a public institution in the interior of the São Paulo state in 2002. Having in mind that many aspects of the human experience construction and organization process are reflected on language, in the investigation developed we compared excerpts from Practicum I and II reports and questionnaires with data from these former-students who are now in-service teachers. Our goal was to demonstrate that feelings like insecurity and anxiety related to the future career, felt especially during the undergraduate program, is still shown in the beginning of the in-service career. Besides being most of the times overcome, the feelings vary according to the student-teachers profile who, in a period of exploration of professional possibilities, structure and restructure the diverse options which life offers them.

Keywords: Teacher Education. English Language. Restructuring.

\section{INTRODUÇÃO}

Em levantamento realizado na área de Educação durante a década de 90 acerca da pesquisa sobre a formação de professores no Brasil, André (2000) constatou que, nos trabalhos sobre licenciaturas, a maior parte enfatiza o estudo das disciplinas pedagógicas e específicas e o currículo de cada curso. Enquanto a atuação do professor também é razoavelmente estudada, a formação inicial recebe menor ênfase, o que demonstra pouca atenção ao aluno da licenciatura. Além disso, faltam investigações sobre as articulações entre as disciplinas pedagógicas e específicas. O que se observa dessa constatação é uma visão fragmentada dos cursos, pois o todo de cada um deles se perde em particularidades e redundâncias. 
Outra revelação do estudo de André (2000) diz respeito à língua estrangeira, nosso objeto de estudo. A distribuição das pesquisas sobre licenciaturas evidenciou apenas cinco trabalhos dedicados ao estudo de línguas, o que demonstra também pouca atenção a esse tema.

Já no que diz respeito à formação docente continuada, André (2000) observa que a maioria dos estudos se concentra em propostas governamentais ou da Secretaria de Educação, em programas e cursos de diferentes instituições, em processos de formação em serviço e na prática pedagógica. Assim como na formação inicial, as pesquisas também se relacionam com aspectos específicos, como uma disciplina, um curso ou uma proposta de formação, e as principais questões levantadas nesses trabalhos coincidem com aquelas da formação inicial: o currículo, a estrutura ou o funcionamento do curso. Mais uma vez, temos um quadro fragmentado e parcial também da formação docente.

Na área de Lingüística Aplicada ao ensino de línguas, a preocupação com a formação inicial e continuada de professores também vem sendo uma constante em âmbito nacional, a ponto de já ter se tornado objeto de estudo de diferentes pesquisas, como aponta Monteiro (2004). O número crescente de estudos sobre a formação de professores de Língua Inglesa também comprova a inquietação dos pesquisadores em entender como os futuros professores estão sendo preparados e como atuam em serviço.

Desde 2002, Silva e Margonari, (2004, 2005) têm pesquisado a formação inicial de professores de Língua Inglesa, o que, de certa forma, vem contribuindo para suprir algumas das lacunas acima apontadas. Essa pesquisa, que está sendo desenvolvida nas disciplinas Prática de Ensino e Estágio Supervisionado de Língua Inglesa I e II em uma universidade federal do Estado de São Paulo, apresenta, até o momento, os seguintes resultados:

(1) Os alunos-professores apóiam-se no referencial teórico estudado para fundamentar suas opiniões acerca da experiência vivida ou mesmo se posicionam com desenvoltura frente às questões relativas ao ensino de língua estrangeira, à sala de aula, ao ensino público e privado, discurso esse que não só serve de apoio para lhes conferir maior segurança, como também é utilizado para discorrer sobre questões advindas da prática. De certa forma, isso demonstra que a integração entre teoria e prática proposta pelo curso atingiu seus objetivos.

(2) Ao longo da licenciatura, o aluno-professor desenvolve uma concepção de linguagem e uma concepção de ensinar e aprender línguas, passando a se conscientizar das responsabilidades de sua futu- 
Professores iniciantes de Língua Inglesa: conflitos e re/estruturações...

ra profissão e das várias competências que a envolvem, e também a questionar sua capacidade de, como educador, se posicionar frente a uma sala de aula, proporcionando e construindo a formação daqueles que deverão atuar nos processos de transformação social. Tais inquietações e questionamentos tomam corpo durante as aulas de Prática de Ensino. Insegurança e tensão se manifestam quanto a sua atuação em sala de aula, e essas sensações conflitantes aumentam durante e após o estágio de observação e regência, pressionando o filtro afetivo (cf. KRASHEN, 1982) desses alunos, o que os leva a questionar a sua escolha profissional.

(3) Dadas as características da licenciatura dupla, é possível identificar três perfis de aluno-professor: (a) o perfil 1 é aquele que, desde o início, se identifica com o curso e tem como objetivo ser professor. $\mathrm{Na}$ maioria das vezes, desenvolve projetos de pesquisa na área de ensinoaprendizagem de Língua Inglesa e ministra aulas, em escolas de idiomas, para alunos particulares e empresas. Esse aluno também tem momentos de insegurança, mas dadas as suas experiências, lida com as incertezas de uma maneira branda; (b) o perfil 2 é aquele que, apesar de se identificar com o curso, não se vê como professor de língua estrangeira, preferindo o ensino de língua materna. Isso implica mais tempo dedicado ao estudo das disciplinas relacionadas à Língua Portuguesa, o que faz com que sua competência lingüístico-comunicativa em língua estrangeira não seja tão desenvolvida, gerando assim mais insegurança para ele; (c) o perfil 3 não se interessa pelo ensino de línguas em geral e não se vê como professor. Esse aluno até desenvolve uma competência lingüístico-comunicativa na língua estrangeira, mas opta pelas diversas possibilidades de trabalho que a graduação em Letras lhe propicia, tais como: pesquisa, revisão e tradução. Devido a essas características, cumpre todas as disciplinas pedagógicas sem se envolver muito com as questões advindas da prática.

(4) Respostas aos problemas e às inquietações em (2) estão relacionadas aos perfis de cada aluno, ou seja, cada qual responde diferentemente aos questionamentos que emergem durante as atividades da disciplina Prática de Ensino. Os perfis que em (3) atuam como uma força no processo de formação do futuro professor são fatores que influenciam suas ações, decisões e re/elaborações do discurso sobre sua futura atuação profissional.

(5) Esse aluno-professor está numa fase de exploração de possibilidades profissionais, por isso estrutura e reestrutura as diversas op- 
ções que a vida lhe oferece e que são comuns à faixa etária em que se encontra (21 a 28 anos). (SIKES, 1985). O tempo, as experiências profissionais e a maturidade talvez o ajudem na decisão final e na superação das dificuldades.

Assim, tendo em vista as lacunas apontadas no estudo de André (2000) e partindo dos dados expostos, procuramos desenvolver um estudo longitudinal, que tem como objetivo acompanhar a trajetória profissional dos professores em início de carreira, egressos do curso de Licenciatura em Letras de uma instituição pública do interior do Estado de São Paulo, desde o ano 2000 até o ano de 2005. Analisando trechos de questionários e relatórios de estágio da disciplina Prática de Ensino e Estágio Supervisionado em Língua Inglesa I e II desses egressos, procuramos cruzá-los com dados desses alunos já em serviço. A pesquisa busca demonstrar que a sensação de insegurança e ansiedade quanto à futura atuação profissional, vivenciada durante o curso, ainda se manifesta no início da carreira docente.

Para o desenvolvimento deste artigo, foram selecionados apenas os egressos do ano de 2002 e foram analisados os vários momentos de re/estruturação profissional pelos quais passaram. Pretendemos demonstrar que as inquietações e inseguranças advindas desse processo, além de, muitas vezes, superadas, variam de acordo com o perfil do aluno-professor.

\section{PROCEDIMENTOS METODOLÓGICOS}

Os dados para esta pesquisa foram extraídos de três fontes: (a) questionários (aplicados no início e ao final da disciplina Prática de Ensino), (b) relatórios de estágio e (c) e-mails enviados a ex-alunos egressos de 2002, em que lhes era solicitado um texto narrativo sobre a sua trajetória de vida profissional, do momento em que tinham deixado a universidade até o ano de 2005, explicitando as experiências e os sentimentos vividos em cada decisão tomada.

Entendendo discurso como atividade produtora de efeitos de sentido entre interlocutores, portanto, atividade comunicativa e o processo de sua enunciação, que é regulado por exterioridade sócio-histórica e ideológica, que determina as regularidades lingüísticas e seu uso (TRAVAGLIA, 1991, p. 25; cf também ORLANDI, 1983), na análise, que é de cunho qualitativo, o processo de escrita (dos questionários, 
Professores iniciantes de Língua Inglesa: conflitos e re/estruturações...

relatórios e narrativas) nos permitiu observar momentos de reflexão e avaliação das experiências vividas pelos sujeitos.

O processo de escrita de qualquer texto, seja ele questionário, relatório ou narrativa, é o momento em que o aluno-professor organiza o discurso e dá sentido às suas experiências, ou seja, é a ocasião em que se retomam inquietações necessárias para instaurar a reflexão sobre teoria e prática, sobre a arte de ensinar, estimulando a maturidade e a definição do posicionamento profissional do futuro educador.

\section{APRESENTAÇÃO E ANÁLISE DOS DADOS}

Acreditando que as escolhas lingüísticas constantes dos questionários, relatórios e narrativas revelam o processo de construção e organização das experiências vivenciadas, passamos à apresentação e analise dos dados. Dos 16 ex-alunos contatados, 13 retornaram a solicitação. Veja-se a tabela 1:

\begin{tabular}{|l|c|c|}
\hline Lecionando & Não lecionando & Total \\
\hline $8(61,5 \%)$ & $5(38,5 \%)$ & $13(100 \%)$ \\
\hline
\end{tabular}

Tabela 1

Desse grupo, 8 (61,5\%) estão exercendo alguma atividade docente e $5(38,5 \%)$ estão atuando em outra área. Dos que estão no magistério, 5 (38,5\%) lecionam Inglês e 3 (23\%), Português. Veja-se a tabela 2 abaixo:

\begin{tabular}{|c|c|c|c|}
\hline \multicolumn{2}{|c|}{ Lecionando } & Não lecionando & Total \\
\hline Inglês & Português & & \\
\cline { 1 - 1 } $5(38,5 \%)$ & $3(23 \%)$ & $5(38,5 \%)$ & $13(100 \%)$ \\
\hline
\end{tabular}

Tabela 2 
As porcentagens indicam que um número razoável de ex-alunos professores egressos de 2002 está seguindo a opção profissional prevista pelo curso de licenciatura. A tabela a seguir ${ }^{1}$ mostra que, excetuando três casos, essas opções relacionam-se ao perfil dos alunos.

\begin{tabular}{|c|c|c|c|c|}
\hline Instituição & $\begin{array}{c}\text { Leciona } \\
\text { Inglês }\end{array}$ & $\begin{array}{c}\text { Perfil } \\
\mathbf{1}\end{array}$ & $\begin{array}{c}\text { Leciona } \\
\text { Português }\end{array}$ & Perfil 2 \\
\hline Escola & $1(\mathrm{M})$ & 1 & $1(\mathrm{~S})$ & $\longrightarrow$ \\
\cline { 4 - 5 } pública & 1 & $1(\mathrm{~A})$ & 2 \\
\hline $\begin{array}{c}\text { Escola } \\
\text { municipal }\end{array}$ & $1(\mathrm{AC})$ & 1 & & \\
\hline $\begin{array}{c}\text { Escola de } \\
\text { idiomas }\end{array}$ & $1(\mathrm{D})$ & 1 & & $\longrightarrow 1$ \\
\cline { 4 - 6 } & $1(\mathrm{G})$ & 2 & & \\
\hline $\begin{array}{c}\text { Universidade } \\
\text { pública }\end{array}$ & $1(\mathrm{~K})$ & 1 & & 2 \\
\hline $\begin{array}{c}\text { Faculdade } \\
\text { Particular }\end{array}$ & & & $1(\mathrm{~J})$ & \\
\hline
\end{tabular}

Tabela 3

Note-se que na escola de idiomas há um ex-aluno perfil 2 lecionando Inglês e na rede estadual pública há um aluno perfil 1 lecionando Português. Além disso, há uma ex-aluna, (D), cujo perfil é 1, mas que, por conta da necessidade, apropriou-se da facilidade propiciada pela dupla licenciatura e atua também na área Língua Portuguesa. Apesar dessas migrações, a maioria dos ex-alunos segue o perfil inicialmente escolhido.

Após o rastreamento e análise das migrações dos alunos já em serviço, apresentamos a análise do cruzamento dos relatórios com os depoimentos enviados por mensagem eletrônica, demonstrando o processo de reestruturações pelas quais todos os perfis passam.

\section{Aluno perfil 1}

A ex-aluna $\mathrm{K}$, que durante o estágio de regência demonstrava não ter tido grandes problemas na prática, visto ser a Língua Inglesa a sua área de atuação, continuou lecionando em escolas de idiomas após a graduação. Nesse percurso, teve decepções, pois precisou se

${ }^{1}$ As letras entre parênteses referem-se às abreviaturas dos nomes dos ex-alunos.

As setas ( $\longrightarrow$ ) indicam as migrações entre as disciplinas Língua Inglesa e Língua Portuguesa, ou seja, mudança no perfil previamente detectado na disciplina Prática de Ensino e Estágio Supervisionado. 
Professores iniciantes de Língua Inglesa: conflitos e re/estruturações...

desligar dessa escola para se dedicar ao processo seletivo da pós-graduação. Por dois anos consecutivos, não conseguiu passar na seleção para o Mestrado em Lingüística Aplicada e Educação de duas instituições públicas do interior do Estado de São Paulo, o que a desanimou:

[...] tentei incansavelmente por dois anos consecutivos, cada vez que prestava, mais eu me decepcionava e me achava incapaz de passar nessa etapa do meu desenvolvimento profissional. Então, me desanimei [...] Acho que ter passado pelo processo seletivo como professora substituta [...] me fez acordar e voltar a sonhar com meu antigo ideal de seguir a carreira acadêmica [...].

O investimento no processo de formação continuada por meio da opção pela pós-graduação stricto sensu a princípio parecia ser um obstáculo de difícil transposição para K, que só foi superado após seu ingresso como professora de uma instituição de ensino superior. Isso fez com que se animasse, retomando sua disposição para continuar sua trajetória acadêmica.

D, outra ex-estagiária perfil 1, com experiência no ensino de Língua Inglesa para crianças, em escolas particulares e de ensino de línguas, afirmava estar "[...] preparada para dar aulas para alunos de escola pública, particular ou em curso de idiomas [...]". Confirmando o seu perfil, ainda continua com o ensino da Língua Inglesa em escolas de línguas. No entanto, para complementar o salário, atua também no ensino de Língua Portuguesa na rede pública, e a carga horária dessa disciplina excede a de Inglês, que é a área de sua preferência. Dando continuidade a sua formação, entrou no mestrado em uma instituição federal e pesquisa na área de ensino-aprendizagem de Língua Inglesa.

Esse caso revela que a dupla licenciatura em Letras atua como um "bem" adquirido pelo aluno-professor, que é utilizado em situações em que precisa se reestruturar econômica e profissionalmente.

S era uma aluna que, apesar de inicialmente ter sérios problemas com a Língua Inglesa, sempre manifestou a vontade de ser professora dessa disciplina, mas sentia-se insegura por causa da lacuna lingüística:

[...] confesso que no começo do curso, não me via como professora, por achar que não tinha competência lingüística [...].

Com muito esforço, no decorrer do curso conseguiu superar parte do problema lingüístico e firmar sua confiança e posição, vendo-se 
como professora dessa língua estrangeira:

[...] mas com o tempo vi que um professor de Língua Inglesa não é formado apenas de competência lingüística, se assim o fosse, os "americanos" poderiam vir ao Brasil e fazer com que alunos falassem Inglês em 24 horas, mas um professor de Língua Inglesa é formado de embasamento teórico, de saber como, porque e para que aprender Inglês.

Atualmente, S passou no concurso do Estado de São Paulo para professor de Língua Portuguesa e, como até aquele momento não havia escolhido sua vaga, é professora eventual dessa disciplina em uma escola estadual de São Carlos (Ensino Fundamental e Médio). Diz estar feliz e que ainda quer lecionar Inglês, pois continua fazendo curso em escola de idiomas.

Essas reestruturações profissionais feitas por S, ou seja, a migração para a área de Português, confirma o papel desempenhado pela dupla licenciatura.

\section{Aluno perfil 2}

Em 2002, G, que se considerava mais professora de língua materna do que de língua estrangeira, ao avaliar sua atuação na Prática de Língua Inglesa, deixa transparecer que o problema da disciplina na rede pública a afetou de alguma maneira e que:

[...] a área de Inglês não seria a minha principal especialização, tendo a necessidade de buscar seus auxílios técnicos quando necessário (de K, sua parceira durante os estágios).

Na época, a dúvida, marcada pela forma verbal seria, que, como modal e não temporal, explicitava atitude do falante sobre aquilo que é dito. G não confessa que a área de Inglês não é a sua principal especialização. Mas, ao invés disso, usa o modal seria, que naquele momento expressa dúvida quanto à possibilidade de vir a atuar como professora de língua estrangeira. Atualmente, ela terminou o mestrado em Literatura, na área de Ciências Sociais, e para se manter, dá aulas de Inglês. Já passou por várias escolas e tem estudado bastante para ensinar essa língua: 
Professores iniciantes de Língua Inglesa: conflitos e re/estruturações...

E também estou dando aulas na Aliança Idiomas. Considerando meu histórico, é um avanço considerável. E esse avanço tem se processado como english speaker and teacher, já que me vi pela primeira vez obrigada a dar aulas todas em Inglês. Isso me deixou de início muito insegura [...] Procuro desde então estudar mais, ler bastante em Inglês, ver mais filmes com legendas em Inglês.

Mesmo com todo esse investimento e satisfação pessoal no ensino da Língua Inglesa, ainda não vê a possibilidade de ficar por muito tempo atuando em língua estrangeira:

O fato é que para mim, dar aulas de Inglês me interessa, sobretudo pelo fato de estar trabalhando como professora, que definitivamente é uma de minhas paixões. [...] Esse talvez seja um lado bom da minha "ignorância" na língua, tenho prazer em aprender com meus alunos, essa troca, acredito ser muito boa para o aprendizado deles [...] Além disso, o aprendizado do Inglês é muito importante para a carreira acadêmica, a qual pretendo seguir, e emprego como professor de língua estrangeira é "um quebra galho" dos mais antigos [...] Desejo terminar meu Mestrado e trabalhar no que realmente gosto, seja na literatura, seja na Sociais [...] Há tantas coisas que tenho estudado, lido, que merecem ser ensinadas. E então, Inglês, just for fun. Quem sabe?

Note-se que, apesar de tudo o que tem feito, G não se sente competente o suficiente para dar aula de língua e reitera a sua vontade de trabalhar com aquilo que gosta: a Literatura. Entretanto, sua consciência acerca do seu menor desenvolvimento com relação à Língua Inglesa mostra-se como um aspecto positivo, que a impulsiona a continuar estudando para melhorar a qualidade de suas aulas. Assim, ao final de seu depoimento, aponta para o seu verdadeiro sonho, sem descartar, mais uma vez, a possibilidade de ensinar Inglês como uma atividade prazerosa.

Ao migrar para um outro perfil, o ex-aluno passa a investir na área a que ele não tinha dado tanta atenção. Essas reestruturações preenchem uma lacuna da graduação, complementando a sua formação em duas licenciaturas.

A ex-aluna P não se via como professora de Inglês, e a expectativa de reger aulas nessa língua lhe causava grande insegurança. No en- 
tanto, o seu grau de envolvimento com a Prática de Ensino foi tanto que, após o estágio, ela já considerava a hipótese de ensinar essa disciplina. Veja-se o depoimento de $\mathrm{H}$, sua parceira durante os estágios, sobre a mudança de atitude de P:

Fiquei satisfeita em perceber, durante as aulas, o interesse e o envolvimento que ela dispensou aos alunos e às atividades desenvolvidas. Porque durante o curso a P dizia que nunca iria dar aula. Após o estágio, já havia mudado de idéia, e passou a considerar essa hipótese.

Apesar de considerar essa hipótese, $\mathrm{P}$, ao rever mais uma vez a sua atuação profissional futura, conclui:

No momento não pretendo atuar na área de Língua Inglesa. Gosto muito da língua e acredito estar preparada para ministrar tal disciplina, pois tenho facilidade em aprendê-la e paciência para ensinála.

De fato, P não está ensinando Inglês. Atualmente está na Itália, fazendo curso de Italiano. Gosta muito dessa língua e quer trabalhar no seu ensino quando aqui retornar, o que significa que continua na área de ensino de língua estrangeira.

A ex-aluna $\mathrm{R}$, com algumas características do perfil 2 mescladas com o 3, ao terminar o curso, volta para a casa dos pais e se questiona:

Medos, anseios e insegurança que se traduziam na pergunta a latejar dentro da minha cabeça: o que fazer da minha vida?

Para dar conta dessa questão, $\mathrm{R}$ tentou se preparar para o mestrado em Análise do Discurso, mas perdeu o prazo para inscrição. Enviou o curriculum vitae para algumas instituições de Ensino Fundamental e Médio, na tentativa de dar aulas de Português e Literatura, mas não conseguiu nada. Dizia que:

Não arriscaria ensinar Língua Inglesa, uma vez que meu Inglês merecia ser esquartejado [...].

Por isso, matriculou-se na Cultura Inglesa de Ribeirão Preto. Desde então, tem estudado bastante o idioma, já prestou o Cambridge First 
Professores iniciantes de Língua Inglesa: conflitos e re/estruturações...

Certificate $^{2}$, conseguiu um trabalho de 10 horas semanais no SAC Self Access Centre da instituição, onde dá apoio a alunos com dificuldades. Apesar de não explicitar que está investindo na futura profissão, ela diz:

Estou estudando agora para prestar o $C A E^{3}$ em dezembro e ano que vem estou me organizando para ir para Brighton fazer um curso de um ano na escola Saint Giles e tirar o Proficiency 4 lá. Se nada disso der certo, começamos de novo com o antigo projeto de vender salgadinhos.

Observa-se a mudança no perfil de $\mathrm{R}$, que migra do ensino de língua materna e passa a investir no ensino de língua estrangeira. Assim como G, não considera sua competência lingüística bem desenvolvida no idioma para ensiná-lo, apesar de ter sido aprovada em um exame de nível avançado de Inglês. Sua conscientização a respeito da necessidade de continuar estudando a língua para se aprimorar é muito positiva, principalmente pelo fato de procurar pela formação continuada em um país falante do Inglês como língua materna.

\section{Aluno perfil 3}

Os alunos perfil 3, apesar de alguma movimentação na direção profissional direcionada pela licenciatura, ainda continuam atuando em outra área. Por exemplo, AM, que trabalha como jornalista, passou no concurso na rede pública para professor de Português, mas não assumiu. Também cursou uma especialização lato sensu em Estudos Literários na UNESP/Araraquara. SA, que trabalha na Nossa Caixa, tentou estrado em Lingüística Aplicada na Unicamp e Lingüística na UFSCar, mas não foi bem sucedido. Já H, que, apesar das tensões, havia feito um bom trabalho de Prática de Ensino, não se sentia preparada para ser professora:

[...] Não pretendo atuar na área de LI, pois entendo que não estou preparada suficientemente para assumir essa responsabilidade. Tenho dificuldade com a LI. O curso diminuiu um pouco essa dificuldade, mas não o quanto eu entendo ser necessário para ensinar.

${ }^{2}$ Primeiro exame de nível avançado da Universidade de Cambridge.

${ }^{3}$ Certificate of Advanced English, exame avançado da Universidade de Cambridge.

${ }^{4}$ Exame posterior ao CAE, o último exame de nível avançado da Universidade de Cambridge. 
Logo após o curso, pensou em se preparar para um curso de pósgraduação, mas não teve condições, pois se envolveu nos assuntos domésticos. Atualmente, apesar de dizer que: "[...] sou uma dona-de-casa convicta. Não tive coragem de abandonar meu posto e me dedicar ao magistério [...]", pensa em preparar um projeto em Lingüística e retornar aos estudos.

Os dados acima apresentados evidenciam que os ex-alunos têm um desejo muito forte de se encontrar e de se aprimorar profissionalmente. Todos, de certa forma, estão fazendo ou já fizeram algum movimento em direção a uma mudança futura, e isso acarreta momentos de dúvidas, angústia e tensão.

\section{CONSIDERAÇÕES FINAIS}

Os dados analisados demonstram que (a) um número razoável de ex-alunos professores egressos de 2002 está seguindo a opção profissional prevista pelo curso de graduação, evidenciando que a licenciatura está cumprindo o seu papel; (b) os ex-alunos algumas vezes migram de perfil e, apesar dessas migrações, a maioria segue a decisão inicialmente tomada; (c) a dupla licenciatura em Letras atua como um "bem" adquirido pelo aluno-professor, que a utiliza em situações em que precisa se reestruturar econômica e profissionalmente; (d) ao migrar para um outro perfil, o ex-aluno passa a refletir sobre a necessidade de um investimento na área a que ele não tinha dado tanta atenção anteriormente. Essas reestruturações, além de preencherem lacunas da graduação, complementam a sua formação em duas licenciaturas e são um avanço em direção à formação continuada.

O cruzamento dos relatórios com os depoimentos enviados por mensagem eletrônica mostra que os ex-alunos-professores ainda estão vivenciando situações de mudança. Nesse processo, são movidos pelo seu perfil: uma força que atua nas suas escolhas e experiências feitas durante o curso de Letras, e por isso ainda enfrentam momentos de ansiedade e insegurança com relação à futura atuação profissional. No processo, essas sensações, além de, muitas vezes, revistas e transpostas, correspondem a um período de instabilidade profissional natural (início de carreira) e são recorrentes na faixa etária em que se encontram (21 a 28 anos). Talvez, a maturidade e as experiências profissionais ajudem na decisão final e na superação das dificuldades.

Tais resultados apontam para a primazia na continuidade deste 
Professores iniciantes de Língua Inglesa: conflitos e re/estruturações...

estudo com dados de alunos egressos de 2003 a 2005 e evidenciam também a necessidade de nos encontrarmos com alguns deles em serviço, ou seja, em situação real de sala de aula. Nossa hipótese é que ainda continuarão sujeitos a inúmeras reestruturações, mas os que seguirem a carreira docente prosseguirão mantendo os níveis de excelência em relação à fundamentação teórico-prática inicialmente recebida no curso de graduação em Letras, bem como persistirão no investimento do processo de formação continuada de professores em serviço.

\section{REFERÊNCIAS}

ANDRÉ, M. E. D. A. A pesquisa sobre formação de professores no Brasil 1990-1998. In: CANDAU, V. M. (Org.). Ensinar e aprender: sujeitos, saberes e pesquisa. Rio de Janeiro: DP \& A, 2000. p. 83-99.

KRASHEN, S. Principles and practice in second language acquisition. New York: Pergamon Press, 1982

MONTEIRO, D. C. Avaliando a produção de pesquisa em lingüística aplicada: foco no ensino-aprendizagem de Inglês como língua estrangeira na UNESP (Araraquara). In: MONTEIRO, D. C. (Org.). Ensino-aprendizagem de língua inglesa em alguns contextos brasileiros. Araraquara: Laboratório Editorial/FCL/ UNESP; São Paulo: Cultura Acadêmica Ed., 2004, p. 15-34.

ORLANDI, E. L. P. A linguagem e seu funcionamento: as formas do discurso. São Paulo: Brasiliense, 1983.

SIKES, P. The life cycle of the teacher. In: BALL, S. J.; GOODSON, I. F. (Ed.). Teachers' lives and careers. London: The Falmer Press, 1985. p. 67-70.

SILVA, A. da; MARGONARI, D. M. Forças atuantes no processo de formação de professores pré-serviço de Língua Inglesa. In: REUNIẪO ANUAL DA ANPED: 40 anos da Pós-graduação em Educação no Brasil, 28., 2005. Caxambu: ANPED, 2005. p. 1-16.

O que revelam os relatórios de estágio supervisionado sobre a formação de professores de Língua Inglesa. Contexturas, v. 7, p. 39-53, 2003/2004.

TRAVAGLIA, L. C. Um estudo textual discursivo do verbo no português do Brasil. 1991. Tese (Doutorado). Instituto de Estudos da Linguagem, Universidade Estadual de Campinas, Campinas, 1991.

Encaminhado em: 03/07

Aceito em: 06/07 